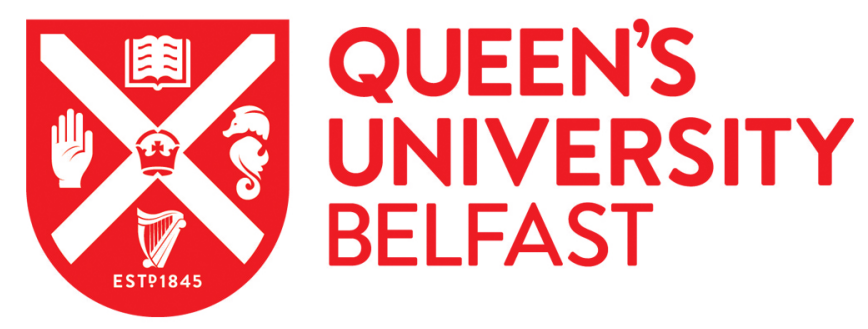

\title{
Major and trace elements in milk and Halloumi cheese as markers for authentication of goat feeding regimes and geographical origin
}

Osorio, M. T., Koidis, A., \& Papademas, P. (2015). Major and trace elements in milk and Halloumi cheese as markers for authentication of goat feeding regimes and geographical origin. International Journal of Dairy Technology, 68(4), 573-581. https://doi.org/10.1111/1471-0307.12213

Published in:

International Journal of Dairy Technology

Document Version:

Peer reviewed version

Queen's University Belfast - Research Portal:

Link to publication record in Queen's University Belfast Research Portal

Publisher rights

(c) 2015 Society of Dairy Technology

This is the peer reviewed version of the following article: Osorio, M. T., Koidis, A. and Papademas, P. (2015), Major and trace elements in milk and Halloumi cheese as markers for authentication of goat feeding regimes and geographical origin. International Journal of Dairy Technology., which has been published in final form at 10.1111/1471-0307.12213. This article may be used for non-commercial purposes in accordance with Wiley Terms and Conditions for Self-Archiving

\section{General rights}

Copyright for the publications made accessible via the Queen's University Belfast Research Portal is retained by the author(s) and / or other copyright owners and it is a condition of accessing these publications that users recognise and abide by the legal requirements associated with these rights.

\section{Take down policy}

The Research Portal is Queen's institutional repository that provides access to Queen's research output. Every effort has been made to ensure that content in the Research Portal does not infringe any person's rights, or applicable UK laws. If you discover content in the

Research Portal that you believe breaches copyright or violates any law, please contact openaccess@qub.ac.uk. 

authentication of goat feeding regimes and geographical origin

3 Maria Teresa Osorio ${ }^{1,2}$, Anastasios Koidis ${ }^{2}$ and Photis Papademas ${ }^{1}$

5

$6{ }^{1}$ Department of Agricultural Sciences, Biotechnology and Food Science, Cyprus

$7 \quad$ University of Technology, Lemesos, Cyprus

$8 \quad{ }^{2}$ Institute for Global Food Security, Queen’s University Belfast, Northern Ireland, UK 9

13 * Corresponding author:

14 Dr Photis Papademas

15 Department of Agricultural Sciences, Biotechnology and Food Science,

16 Cyprus University of Technology,

$17 \quad$ PO Box 50329

18 3603, Lemesos,

19 Cyprus

20 Tel.: +35725002581. Fax: +35725002652

21 E-mail: photis.papademas@cut.ac.cy 


\section{ABSTRACT}

2 Sixty samples of milk $(n=24)$, Halloumi cheese $(n=23)$ and local grazing plants (i.e.

3 shrubs) ( $\mathrm{n}=13)$ were collected over a year from dairy farms located on three different

4 locations of the island of Cyprus. Major and trace elements (Ag, Al, B, Ba, Co, Fe, $\mathrm{Li}$,

$5 \mathrm{Mn}, \mathrm{Se}, \mathrm{Sr}, \mathrm{Y}, \mathrm{Ca}, \mathrm{K}, \mathrm{Mg}, \mathrm{Na}$ and P) were quantified using Inductively Coupled

6 Plasma-Atomic Emission Spectroscopy (ICP-AES). Milk and Halloumi cheese

7 produced in different geographical locations of Cyprus presented significant

8 differences in the concentration of some of the elements analysed. Principal

9 component analysis showed grouping of samples according to region of production

10 for both, milk and cheese samples. By applying a stepwise canonical discriminant

11 analysis, a good discrimination of milk (88.5\% of the samples correctly assigned to

12 the area of production) and cheese (100\% of the samples correctly classified)

13 according to geographical origin and feeding regimes was obtained. These findings

14 show that the assay of element compounds can provide useful fingerprints for the

15 characterisation of dairy products according to geographical location and production 16 system.

18 Keywords: authentication, elemental markers, geographical origin, feeding regime, 19 goat milk, Halloumi cheese 


\section{INTRODUCTION}

2 The differentiation of dairy products obtained from different regions in Cyprus

3 (highland areas i.e. Paphos vs lowland areas i.e. Kofinou) is of high importance since

4 milk and cheese produced in highland areas could carry a 'quality label' i.e.

5 "mountain product" (EC 1151/2012). It has to be proved, however, that they are

6 distinctively different from milk and cheese produced in lowland areas. Products

7 endorsed with a quality label have an added value and benefit for the producers and

8 consumers alike. The production of goat and sheep milk in Cyprus is about 38 million

9 L year ${ }^{-1}$ with approx. 21 million L (55 \%) used for the production of Halloumi cheese

10 (Statistical Service Cyprus, 2014). Halloumi is the traditional goat and sheep cheese

11 produced in Cyprus that has gained international recognition with exports of 10,530t

12 currently valued at 70 million $€$ annually (Statistical Service Cyprus, 2014). It is a

13 semi-hard, elastic, easily sliceable cheese that can be grilled, fried, or cooked whilst

14 retaining its texture. It has a pleasant milky flavour while salt adds to its taste. It is

15 made primarily of a mixture of goat and sheep milk (usually at 70:30 ratio), while

16 during the last 20 years cow's milk has also been introduced to the milk mixture

17 (Papademas, 2006). Although Halloumi cheese has not been yet assigned to any EU

18 quality schemes (such as Protected Designation of Origin -PDO- or Protected

19 Geographical Indication -PGI-), in order to protect its authenticity, some parameters

20 such as area of origin and processing of the milk must be established. These

21 characteristics depend on the original features of the milk and hence on the conditions

22 under which the milk has been produced such as feeding regime of the animals or

23 geographical location. The composition of the goat/sheep milk depends on production

24 factors constituting the farming system such as genotype, agro-climatic conditions

25 and feeding and milking of animals (Morand-Fehr, Fedele, Decandia, \& Le Frileux, 
1 2007). Due to the regime under which the goats and sheep are raised (usually goats

2 are kept outdoors several months per year), the feeding factor has been proven to be

3 one of the main factors influencing the composition of the milk (Morand-Fehr et al.,

4 2007) and it is linked inevitably to geographical origin where the feed ingested by the

5 animals is growing. Consequently, geography of the farming area might affect the

6 kind of plants that are available to the animals. For instance, highlands farm suitable

7 for extensive livestock production where no other agricultural practices are possible,

8 have a wider botanical diversity than lowlands where agricultural practices are

9 suitable (Mariaca et al., 1997).

10 Previous studies have established a relationship between some aspects of the chain;

11 plant-animal-milk-cheese and have proposed different compounds as markers of that 12 chain for tracing cheeses. For instance, quantification of specific compounds or 13 groups of compounds in milk and cheese that can act as dietary and geographical sites 14 markers has been reported; these include fatty acids (Collomb, Bütikofer, Sieber, 15 Jeangros, \& Bosseta, 2002), volatile compounds -mainly terpenes (Pillonel, Ampuero, 16 Tabacchi, \& Bosset, 2003; Zeppa, Giordano, Lombardi, Gerbi, 2003) and vitamin A 17 and E (Agabriel et al., 2007).

18 The use of multi-element analysis has been proved to be a good tool for origin 19 authentication purposes of different foods such as onions (Ariyama et al., 2007; 20 Chope \& Terry, 2009; Furia, Naccarato, Sindona, Stabile, \& Tagarelli, 2011), wine 21 (Taylor, Longerich \& Greenough, 2003; Coetzee et al., 2005), tea (Moreda-Piñeiro, 22 Fisher \& Hill, 2003) and tomatoes (Lo Feudo, Naccarato, Sindona, \& Tagarelli, 2010), 23 milk i.e. cow vs buffalo (Benincasa, Lewis, Sindona, \& Tagarelli, 2008) The 24 aforementioned technique has also been applied for origin authentication purposes to 25 cheeses (Suhaj \& Koreňovská, 2008). The latter authors revealed significant 
1 correlations between the concentration of elemental markers in soil and their content

2 in grass, milk and cheese. However, there is no study on the utility of mineral and

3 trace element analysis as a tool for discrimination of milk according to geographical

4 regions and/or feeding regimes. For the latter purpose, multi-element analysis has

5 been used in combination with multi-element isotope analysis in milk (Sacco et al.,

6 2009) and cheese (Pillonel et al., 2010; Bontempo et al., 2011). Factors influencing

7 the mineral and trace element concentrations in dairy products were studied by

8 Herrera et al. (2006). The concentration of minor and trace elements differed amongst

$9 \quad$ varieties of dairy products, i.e. raw milk vs whey vs fresh cheese vs semi-hard cheese;

10 these differences were also revealed by Coni et al. (1996). However, the region of

11 production was found to have less influence on the mineral concentration of dairy

12 products than the season of production (Herrera et al., 2006).

13 This study is based on the existing goat/sheep production systems from three different

14 areas of Cyprus well known for Halloumi cheese production. Available information

15 from the geochemical atlas of soils in Cyprus revealed substantial differences between

16 the three points of interest where the farms are located. Consequently, this paper

17 aimed at (a) investigating the differences of the metallic and trace elements in grazing

18 plants, goat/sheep milk and Halloumi cheese originating from those three areas and (b)

19 establishing a relationship between these elements as potential markers and the region

20 of production. Potential elemental markers could be used to assess authentication of

21 dairy products in Cyprus. 


\section{MATERIAL AND METHODS}

\section{2.1. Experimental design}

3 Three goat/sheep farms from different locations in Cyprus were studied. Group A

4 animals were bred in Anogyra area, a region in the SW of Cyprus where all animals

5 were $100 \%$ Damascus goat breed and grazed for $6 \mathrm{~h} / \mathrm{d}$ on a land mainly characterised

6 by the following plants: Pistacia lentiscus and Ceratonia siliqua and 18h/d kept in

7 indoor confinement. Indoor animals were offered a diet based on concentrate and

8 forage (mean daily DM intake per animal of $1 \mathrm{~kg}$ concentrate and ad libitum forage i.e.

9 straw). A typical concentrate composition is: $615 \mathrm{~g} \mathrm{~kg}^{-1}$ barley, $230 \mathrm{~g} \mathrm{~kg}^{-1}$ soya, $130 \mathrm{~g}$

$10 \mathrm{~kg}^{-1}$ corn grains, $25 \mathrm{~g} \mathrm{~kg}^{-1}$ mineral/vitamin premix containing calcium, phosphorus,

11 sodium and magnesium. All animals were milked twice daily. Group B animals were

12 bred in Kofinou area where all animals were 100\% Damascus goat breed with a

13 feeding regime consisting of $2 \mathrm{~h}$ free-grazing and $22 \mathrm{~h}$ indoor feeding. Grazing in the

14 land where group B animals were raised was minimal and mainly characterized by the

15 plant species Malva sylvestris. Indoor animals were fed concentrate and straw (mean

16 daily DM intake per animal of $3 \mathrm{~kg}$ concentrate and 0.8-1.0 kg forage i.e. straw). The

17 composition of the concentrate was similar to the one mentioned above. Animals from

18 group $\mathrm{C}$ were bred in the region of Paphos in the west part of Cyprus. In this area,

19 goats and sheep after morning milking were led to the Paphos highlands in the spring

20 period (from March to June) and to the lowlands in the winter period (from September

21 -February) for approximately 8-10 h/d. Grazing during the very hot summer months

22 (July, August) is generally limited. The highland flora is characterised by the

23 following plants: Thymus capitatus, Calicotome villosa, Myrtus communis, Olea

24 europaea, Quercus coccinea, Inula viscosa, Cistus creticus, Sarcopoterium spinosum,

25 Crataegus azarolus, Helichrysum italicum, and a mixture of plants growing together 
1 such as Plantago lanceolata, Medicago truncatula and Poaceae, whereas the lowland

2 flora is characterized by the straw remained after cereal harvest. When animals are

3 indoors they are offered ad libitum straw and barley in addition to feed concentrates.

\section{$4 \quad$ 2.2. Sampling}

5 A total of 24 bulk-tank milk samples (approx. $1000 \mathrm{~mL}$ ) were collected from March

62011 to February 2012 from the three dairy farms in Cyprus and 23 samples of

7 Halloumi cheese made from the same batch of milk were also collected. Halloumi

8 cheese was elaborated in each farm following the standard manufacturing procedure

9 excluding a dry mint coating of the cheeses to avoid possible external sources rather

10 than milk. Additionally, 13 samples of the predominant grazing plants were collected

11 (March - June 2011) from the three sampling regions and submitted to multi-element

12 analysis. All samples were stored at $-80{ }^{\circ} \mathrm{C}$ for subsequent analysis.

\section{2.3. Chemicals}

14 The reagents used for mineralization, $\mathrm{HNO}_{3}$ (65\%) and $\mathrm{H}_{2} \mathrm{O}_{2}$ (30\%) were provided 15 by Merck (Darmstadt, Germany). A multi-element solution of Ag, Al, Ba, Be, Bi, Cd, $16 \mathrm{Co}, \mathrm{Cr}, \mathrm{Cs}, \mathrm{Cu}, \mathrm{Ga}, \mathrm{In}, \mathrm{Li}, \mathrm{Mg}, \mathrm{Mn}, \mathrm{Mo}, \mathrm{Ni}, \mathrm{Pb}, \mathrm{Rb}, \mathrm{Sr}, \mathrm{Tl}, \mathrm{V}$ and $\mathrm{Zn}\left(10 \mathrm{mg} \mathrm{L}^{-1}\right)$ and $17 \mathrm{Ca}, \mathrm{Fe}, \mathrm{K}$ and $\mathrm{Na}\left(100 \mathrm{mg} \mathrm{L}^{-1}\right)$ (Fluka, Buchs, Switzerland) as well as 5 individual 18 standards, As, Se and Y (Merck, Germany), B and P (Fluka, Switzerland) were used 19 to prepare the calibration standards. The accuracy of the method was assessed by 20 analysing the certified reference material BCR-063R (Skim milk power, IRMM -

21 European Commission-Joint Research Centre, Geel, Belgium).

\section{2.4. Analytical procedure}

23 Milk and Halloumi cheese samples were defrosted overnight. Milk samples were

24 thoroughly mixed prior to digestion. Aliquots of $3 \mathrm{~mL}$ of milk were weighed directly 25 into the digestion vessels and $9 \mathrm{~mL}$ of $\mathrm{HNO}_{3}$ (65\%) was added to each vessel. 
1 Halloumi samples were cut into small cubes and ground using a manual grater.

2 Aliquots of $0.65 \mathrm{~g}$ of Halloumi cheese were weighed directly into the digestion

3 vessels and $4 \mathrm{~mL}$ of $\mathrm{HNO}_{3}(65 \%)$ and $2 \mathrm{~mL} \mathrm{H}_{2} \mathrm{O}_{2}$ (30\%) were added to each vessel

4 as mentioned in the study of Bontempo et al. (2011). Fresh plants were dried in an air-

5 oven (Memmert, Germany) at $75^{\circ} \mathrm{C}$ for $48 \mathrm{~h}$ and dry material was ground and

6 homogenised using an electric mixer (Taurus, Spain). About $0.5 \mathrm{~g}$ of each dry plant

7 was weighed into the digestion vessels. Digestion was performed by adding $7 \mathrm{~mL}$ of

$8 \mathrm{HNO}_{3}(65 \%)$ and $2 \mathrm{~mL} \mathrm{H} \mathrm{O}_{2}$ (30\%) to each vessel.

9 All samples were digested in close vessels using a Milestone Ethos 1 microwave oven

10 (Milestone Srl., Milan, Italy). The operating conditions used for the microwave

11 digestion system are shown in Table 1. All samples were digested once and analysis

12 was carried out in triplicates. Additionally, two milk samples and two Halloumi

13 samples were digested in triplicate and duplicate respectively, in order to check the

14 reproducibility of the digestion procedure and analysed in triplicate. After digestion

15 and cooling down at room temperature, all the digested liquors were quantitatively

16 transferred into volumetric flasks and made up to volume $12 \mathrm{~mL}$ for milk digested

17 liquors, $25 \mathrm{~mL}$ for Halloumi cheese digested liquors and $15 \mathrm{~mL}$ for plant digested

18 liquors with ultrapure water obtained from a Elix Milli-Q system (Millipore, USA). 1

$19 \mathrm{~mL}$ of each digested liquors was transferred a second time to a test plastic tube and

20 made up to a volume $20 \mathrm{~mL}$ using ultrapure water in order to quantify those elements

21 present in high concentration in the samples (Ca, K, Mg, Na, P and Zn).

22 Analysis of Ag, Al, Ba, Be, Bi, Cd, Co, Cr, Cs, Cu, Ga, In, Li, Mg, Mn, Mo, Ni, Pb,

$23 \mathrm{Rb}, \mathrm{Sr}, \mathrm{Tl}, \mathrm{V}, \mathrm{Zn}, \mathrm{Ca}, \mathrm{Fe}, \mathrm{K}$ and Na were determined by Inductively Coupled Plasma-

24 Atomic Emission Spectrometry (ICP-AES) (ICPE-9000 Shimadzu, Japan). Instrument 
1 operating conditions were: radiofrequency power, $1200 \mathrm{~W}$; plasma gas flow, 10.0

$2 \mathrm{~L} / \mathrm{min}$; auxiliary gas flow, $0.6 \mathrm{~L} / \mathrm{min}$; carrier gas flow $0.7 \mathrm{~L} / \mathrm{min}$.

3 To assess the accuracy of the whole process, a certified reference material, BCR-063R

4 (Skim milk power, IRMM - European Commission-Joint Research Centre, Geel,

5 Belgium) was subjected to the same analytical process as other samples and analysed

6 in triplicate (Table 2).

7 A minimum of two spiked samples with five elements: P (20 ppm or $20 \mu \mathrm{g} / \mathrm{g}$ ), Na (20

$8 \mu \mathrm{g} / \mathrm{g})$, Ca $(20 \mu \mathrm{g} / \mathrm{g}), \mathrm{K}(10 \mu \mathrm{g} / \mathrm{g})$ and $\mathrm{Mg}(10 \mu \mathrm{g} / \mathrm{g})$ were analysed at the end of each

9 of the three analytical runs (cheese, milk and plants) for quality control and reliability 10 purposes.

11 Blanks were run at the beginning of each analytical batch to calculate the limit of 12 detection and quantification. Limit of detection (LOD) and limit of quantification 13 (LOQ) were defined as 3 and 10 times respectively, the standard deviation of the 14 signal from reagent blanks after correction for sample weight and dilution. Elements 15 below the LOQ value were not accepted.

\subsection{Calibration procedure}

17 Calibration standards were prepared by diluting a multi-element solution containing $1810 \mathrm{mg} \mathrm{L}^{-1}$ of each of the following elements, $\mathrm{Ag}, \mathrm{Al}, \mathrm{Ba}, \mathrm{Be}, \mathrm{Bi}, \mathrm{Cd}, \mathrm{Co}, \mathrm{Cr}, \mathrm{Cs}, \mathrm{Cu}$, 19 Ga, In, Li, Mg, Mn, Mo, Ni, Pb, Rb, Sr, Tl, V and Zn and $100 \mathrm{mg} \mathrm{L}^{-1}$ of Ca, Fe, K, Na 20 as well as five individual standards not included in the multielement solution. These 21 five standards were $\mathrm{As}, \mathrm{B}, \mathrm{P}$, Se and $\mathrm{Y}$ in a solution of $0.08 \% \mathrm{HNO}_{3}$. The 22 concentration range for the elements $\mathrm{Ag}, \mathrm{Al}, \mathrm{Ba}, \mathrm{Be}, \mathrm{Bi}, \mathrm{Cd}, \mathrm{Co}, \mathrm{Cr}, \mathrm{Cs}, \mathrm{Cu}, \mathrm{Ga}$, In, $23 \mathrm{Li}, \mathrm{Mg}, \mathrm{Mn}, \mathrm{Mo}, \mathrm{Ni}, \mathrm{Pb}, \mathrm{Rb}, \mathrm{Sr}, \mathrm{Tl}, \mathrm{V}$ and $\mathrm{Zn}$ was $0.001-0.2$ whereas the 24 concentration range for the elements $\mathrm{Ca}, \mathrm{Fe}, \mathrm{K}$ and $\mathrm{Na}$ was $0.01-2 \mu \mathrm{g} / \mathrm{g}$. The set of 25 calibration standards were analysed at the beginning of the sample runs and a seven- 
1 point calibration curve was used for quantitative analysis. Six of those elements (Ca,

$2 \mathrm{~K}, \mathrm{Mg}, \mathrm{Na}, \mathrm{P}$, and $\mathrm{Zn}$ ) were present in high concentration in the dairy samples;

3 therefore a new set of calibration standards were prepared by diluting these six

4 elements in a solution of $0.08 \% \mathrm{HNO}_{3}$. The concentration range for $\mathrm{Zn}$ was $0.1-2.5$

5 ppm whereas for $\mathrm{Ca}, \mathrm{K}, \mathrm{Mg}, \mathrm{Na}, \mathrm{P}$ and $\mathrm{Zn}$ was $2-50 \mu \mathrm{g} / \mathrm{g}$. For the quantitative

6 analysis of those six elements, a five-point calibration curve was built.

\section{$7 \quad$ 2.6. Statistical analysis}

8 An exploratory one-way analysis of variance (ANOVA) for each measured variable

9 followed by a Tukey post hoc test was performed to assess the significance of the 10 differences among groups of samples of different production regimes using SPSS 20.0

11 (IBM SPSS Statistics, Inc., Chicago, IL). The data were also subjected to multivariate 12 statistical analysis to evaluate the possibility of differentiating milk and cheese 13 according to production regimen. Principal component analysis (PCA) was performed 14 to obtain a better perception of differences between elements of milk and Halloumi 15 cheese from different locations within Cyprus.

16 Canonical discriminant analysis (CDA) was performed to evaluate whether 17 discrimination of samples on the basis of the production regimen could be based on 18 the determined multi-elemental profile and to verify which elements contribute 19 toward classification. A stepwise method was used to select the most significant 20 variables and to exclude the redundant ones from the model. The procedure generates 21 a set of canonical discriminant functions based on the selected variables that provide 22 the best discrimination between the groups. Those functions can be applied to new 23 samples that have measurements for the determined elements but come from 24 unknown dietary groups. The statistical significance of each discriminant function 25 was evaluated on the basis of the Wilks' $\lambda$ factor after the function was removed. To 
1 verify the stability of the model, a "leave-one-out" cross validation was performed.

2 The success of the discrimination was measured by the proportion of cases correctly

3 classified using this cross-validation.

4

\section{3. RESULTS AND DISCUSSION}

\subsection{Milk}

Mineral and trace elements concentrations of cheese produced in three different areas of Cyprus as well as the milk used to elaborate those cheeses are shown in Table 3. Five elements (Li, Ca, Mn, Zn, Sr) showed significant differences according to the producing areas of the milks. Milk samples from the highland area (Paphos) presented higher concentrations of $\mathrm{Li}$ and $\mathrm{Ca}(\mathrm{P}<0.05)$ than those from the other two producing areas. In contrast to the findings of Garcia et al. (2006) who found that Ca concentrations of goats' dairy products were affected by seasonal variation rather than by the region of production, Ca levels were found to be affected by the region of production in the current study. While milks from lowland areas (Anogyra and Kofinou) differed significantly in the concentration of $\mathrm{Mn}(\mathrm{P}<0.05)$, milks from Kofinou and Paphos differed significantly $(\mathrm{P}<0.05)$ in the concentration of $\mathrm{Zn}$. The differences in the mean concentration of $\mathrm{Zn}$ in milk from Kofinou and Paphos could be attributed to the type of goats' diet since $\mathrm{Zn}$ content in milk was found to be dependent on this (Garcia et al., 2006). Additionally, the concentration of Sr was significantly higher $(\mathrm{P}<0.05)$ in milk from Kofinou than in milk from Anogyra and Paphos. Although a high variability in the concentration of $\mathrm{Sr}$ in the milk samples from Kofinou was observed (Figure 1), it is clear that no overlap between Kofinou samples and those from the other two regions occurred. 
1 The higher concentrations of some of the minerals could be explained by the different

2 animals' diets (i.e. different type of grazing plants). Goats from Paphos are grazing

3 for prolonged periods of the year outdoors. As a consequence, higher levels of Zn, Ca

4 and Li occur in the milks from Paphos compared to the other areas, which are

5 reflected in the higher content of those minerals in the plants the animals grazed.

6 Element concentrations of plants collected from the three regions of production are

7 presented in Table 4 . In terms of geographical location, wide plant diversity exists in

8 the highlands of Paphos where animals grazed ad libitum. Plants are known to

9 accumulate minerals and metals essential for their growth from the environment.

10 Principal component analysis (PCA) was applied to a data set composed of five 11 variables and 24 dairy samples. The variables were the elements that showed 12 significant differences between areas of production in the ANOVA, Li, Ca, Mn, Zn 13 and Sr. The score plot on the first two principal components (PCs) is showed in 14 Figure 2. The $100 \%$ original data variance was summarized by five uncorrelated 15 principal components. Only the first two PCs accounted for a significant piece of 16 information with eigenvalues $\geq 1$ and they accounted for $61 \%$ of the total variance. 17 Samples from Kofinou and Paphos are clearly separated on the first principal 18 component, while samples from Anogyra and the other two regions (Kofinou and 19 Paphos) are mainly separated on the second principal component. Li, Sr and Zn have 20 the highest loading coefficients on the PC1, being negative for $\mathrm{Sr}$ and positive for $\mathrm{Li}$ 21 and Zn. On the other hand, Mn and Ca have the highest loading coefficients on the 22 PC2, both of them being positive. Samples from Kofinou were all situated the bottom 23 left of the score plot due to their high Sr content. Anogyra showed an almost24 complete separation from the other two groups with the exception of two samples, 
1 mainly due to their high Mn and Ca content. Paphos samples were mainly situated at

2 the bottom right of the score plot due to their high content of $\mathrm{Zn}$ and $\mathrm{Li}$.

\subsubsection{Canonical discriminant analysis}

A canonical discriminant analysis (CDA) was performed to classify milk according to region of origin on the basis of minor and trace elements. CDA was applied to five variables (same as above, $\mathrm{Li}, \mathrm{Mn}, \mathrm{Sr}, \mathrm{Ca}$ and $\mathrm{Zn}$ ) considering all the milk samples from three different regions of origin (Anogyra, Kofinou and Paphos). A stepwise method was used in order to identify redundant variables and exclude them from the model. In this case, three elements were selected due to their significant contribution to the discrimination of milk samples: $\mathrm{Ca}, \mathrm{Sr}$ and $\mathrm{Zn}$. The results showed two discriminant functions. Both discriminant functions were statistically significant for the discrimination (Wilk's $\lambda<0.2$ ), with the first being the most significant $(\lambda<0.002$ ). The first function explained $98 \%$ of the variance and it was mainly correlated with Ca. The second discriminant function accounted for $2 \%$ of the variation and it was mainly correlated with Sr and Zn. In the classification results (Table 3), 88.5\% of the original grouped cases were correctly classified. A slightly higher correct classification (92.3\%) was obtained when cross-validation analysis was performed. In the crossvalidation, all samples from Anogyra and Paphos were correctly classified, whereas two samples from Kofinou were misclassified. This suggests that $\mathrm{Ca}$, Sr and Zn markers could be used as a tool in identifying milk originated from the three Cypriot regions.

The separation between the three regions of origin in the discriminant space was checked by plotting the first and second discriminant functions shown in Figure 3. Results showed a good separation between the three groups with the exception of two samples from Paphos that were clustered with samples from Anogyra. 


\subsection{Halloumi cheese}

2 As expected, cheeses presented higher mean concentrations of all elements analysed

3 than the milk used for their production. This is due to the technological process for

4 elaboration of cheeses and the fact that cheeses are more concentrated (less moisture

5 content) product. Eight elements showed significant differences according to the

6 region of origin of the Halloumi cheeses, $\mathrm{Ag}, \mathrm{Ba}, \mathrm{Ca}, \mathrm{K}, \mathrm{Mg}, \mathrm{Mn}, \mathrm{P}$ and $\mathrm{Sr}$.

7 Additionally, significant differences were observed in the concentration of Na. Since

8 salt $(\mathrm{NaCl})$ is added as an ingredient in the cheese making process, $\mathrm{Na}$ (sodium)

9 should not be considered a possible marker of region of origin, thus it was excluded

10 from the models. However, cheeses from Paphos presented higher content of Na

11 followed by cheeses from Anogyra and Kofinou, respectively. Organoleptic 12 characterisation (i.e. sensory analysis) of Halloumi cheese clearly indicated that 13 cheeses from Paphos were saltier than those from Anogyra and Kofinou (data not 14 shown). Moreover, milk samples from the three areas of production had a similar $\mathrm{Na}$ 15 content, suggesting the addition of $\mathrm{NaCl}$ during cheese making affects the final 16 concentration. The concentrations of $\mathrm{Li}$ and $\mathrm{B}$ were below the detection limits of the 17 determination. Comparing the cheeses from the three regions, Halloumi from 18 Anogyra had higher $(\mathrm{P}<0.01) \mathrm{Ag}, \mathrm{K}$ and $\mathrm{Mn}$ mean concentration than the 19 corresponding mean values in Halloumi from Kofinou and Paphos. The high levels of 20 Ag could be explained by the fact that the surface soil of the Anogyra region presents 21 higher levels of Ag than the soil of the other two regions. Comparing with fresh and 22 semi-hard cheeses from Tenerife (Spain) (Garcia et al., 2006), Halloumi cheese from 23 the three regions had similar concentrations of K. Cheese samples from Kofinou had 24 higher levels $(\mathrm{P}<0.01)$ of $\mathrm{Ba}, \mathrm{P}$ and $\mathrm{Sr}$ than Halloumi from the other two regions. The 25 concentration of $\mathrm{Ba}$ in both the surface soil and the subsoil was higher in the region of 
1 Kofinou than that found in the other two regions (Cohen, Rutherford, Morisseau, \&

2 Zissimos, 2011). Higher amount of Sr observed in the soil could also contribute to the

3 mean concentration of Sr present in Halloumi cheese samples from Kofinou.

4 PCA on cheese samples ( $\mathrm{n}=23$ ) was performed using five (Ag, $\mathrm{Ba}, \mathrm{K}, \mathrm{Mn}, \mathrm{Sr}$ ) of the

5 eight elements that showed significant differences between areas of production in the

6 ANOVA. Ca, $\mathrm{Mg}$ and $\mathrm{P}$ showed significant differences between the areas of

7 production, and were excluded from the PCA. The reason is that these minerals are

8 rather abundant in milk and their levels are not production depended. It is not

9 expected goat's milk to have different quantities of major elements even from

10 different areas since goat milk is from the same or similar breeds. These minerals,

11 therefore, they cannot serve as biomarkers.

12 Data processing with PCA showed that the three different production areas are well

13 separated in the score plot of the first two principal components (Figure 4), which

14 accounted for $73 \%$ of the total variance. 'Lowland' cheeses, however, are better

15 correlated with discriminant elements, i.e. have highest loading coefficients on one of

16 the PCs, than 'highland' cheeses. More specifically, 'lowland' Anogyra and Kofinou

17 samples are defined by their distinct $\mathrm{Ag}, \mathrm{Mn}$ and $\mathrm{K}$ content and $\mathrm{Ba}$ and Sr content,

18 respectively. No particular element was found predominant from the highland

19 (Paphos) cheeses that made this area of production be sufficiently different from

20 lowland cheeses in terms of the elemental composition.

\section{$21 \quad$ 3.2.1. Canonical discriminant analysis}

22 CDA was applied to the concentration of the five elements of each sample mainly

23 contributing to separation of the groups in the PCA. These elements were Ag, Ba, K,

$24 \mathrm{Mn}$ and Sr. Following the stepwise procedure, three elements (K, Mn and Sr) were

25 selected due to their significant contribution to the discrimination of Halloumi 
1 samples. The two first canonical discriminant functions were used in the analysis.

2 Both discriminant functions were statistically significant for the discrimination

3 (Wilk's $\lambda<0.3$ ), with the first being the most significant $(\lambda<0.05)$. The first function

4 explained $65 \%$ of the variance and it was mainly correlated with Sr. The second

5 discriminant function accounted for 35\% of the variation and it was mainly correlated

6 with $\mathrm{K}$ and $\mathrm{Mn}$. The scores of the two canonical discriminant functions (Figure 5)

7 showed a clear separation between the three regions of cheese production. This good

8 separation of groups was confirmed by the classification results (Table 4); $100 \%$ of

9 the samples were correctly classified with $95.7 \%$ cross-validated correctly classified

10 samples. In the cross-validation, all samples from Anogyra and Paphos were correctly

11 classified and only one sample from Kofinou was misclassified. In a similar study,

12 different elemental markers of origin ( $\mathrm{Ba}, \mathrm{Cu}, \mathrm{Cr}, \mathrm{Hg}, \mathrm{Mg}, \mathrm{Mn}, \mathrm{Ni}$ and $\mathrm{V}$ ) were

13 successfully (>90\% accuracy) able to classify Slovakian sheep cheeses from different

14 producing agricultural areas (Suhaj \& Koreňovská, 2008) which highlighted the

15 potential of element content as markers for geographical identification of area of 16 cheese production. In the current study, $\mathrm{K}, \mathrm{Mn}$ and $\mathrm{Sr}$ could be considered as markers 17 of origin for the identification of Halloumi cheese originating from different locations

18 of the island of Cyprus. From these, $\mathrm{Sr}$ is the only elemental marker of origin that 19 contributed to the successful identification of both milk and cheeses.

\section{4. CONCLUSIONS}

22 The vertical investigation of geochemical information (soil data leading to grazing

23 plants leading to milk leading to cheese, - here Halloumi cheese) is an essential 24 approach for authenticating the geographical origin of milk/cheese production that has 25 been attempted for some other products in the past. Its implementation, however, in 
1 traditional dairy products can sometimes prove to be challenging. In the current study,

2 trace elements ( $\mathrm{Mn}$ and $\mathrm{Sr}$ ), are not present in high concentration in milk and cheese,

3 do not originate from cheesemaking equipment, nor are present in high quantities

4 naturally in milk or in feeding concentrates. These two trace elements have

5 demonstrated the capacity to provide a traceability record. Particularly strontium (Sr)

6 could be used as a potential biomarker for distinguishing at least the samples from one

7 area of production (i.e. Kofinou area) since the results could be well correlated for soil

8 data, milk and cheese as a final product. It is true that in order to build a more robust

9 model, more sample types (i.e. water from the animal farms) should be added and

10 overall sample numbers should be increased. On the other hand, if elemental data is

11 used in conjunction to other characteristic chemical indexes (i.e. fatty acid profiles,

12 plant terpenes, isotope analysis), a more holistic and accurate picture of halloumi

13 cheese authenticity could be created.

\section{Acknowledgements}

16 The authors would like to acknowledge the farmers/Halloumi cheese producers for

17 kindly providing the samples throughout this study. Also special thanks to A.

18 Zissimos of the Cyprus Geological Survey for providing geochemical soil data of

19 Cyprus. The study was funded by the Cyprus University of Technology. 
2

3

4

5

6

(b) Microwave digestion program for milk samples

\begin{tabular}{|c|c|c|c|}
\hline Step & Time $(\min )$ & Temperature $\left({ }^{\circ} \mathrm{C}\right)$ & Power $(\mathrm{W})$ \\
\hline 1 & 3.00 & $25-140$ & 1000 \\
\hline 2 & 4.00 & $140-150$ & 1000 \\
\hline 3 & 7.00 & 150 & 1000 \\
\hline 4 & 10.00 & $150-180$ & 1000 \\
\hline 5 & 20.00 & 180 & 1000 \\
\hline
\end{tabular}

Table 1. Microwave digestion settings for milk, Halloumi cheese and plant samples

(a) Microwave digestion program for Halloumi cheese samples

\begin{tabular}{|c|c|c|c|}
\hline Step & Time $(\min )$ & Temperature $\left({ }^{\circ} \mathrm{C}\right)$ & Power $(\mathrm{W})$ \\
\hline 1 & 7.00 & 90 & 1000 \\
\hline 2 & 5.00 & 170 & 1000 \\
\hline 3 & 5.00 & 210 & 1000 \\
\hline 4 & 20.00 & 210 & 1000 \\
\hline
\end{tabular}

(c) Microwave digestion program for plant samples

\begin{tabular}{|c|c|c|c|}
\hline Step & Time $(\mathrm{min})$ & Temperature $\left({ }^{\circ} \mathrm{C}\right)$ & Power $(\mathrm{W})$ \\
\hline 1 & 10.00 & 180 & 1000 \\
\hline 2 & 10.00 & 180 & 1000 \\
\hline
\end{tabular}

8

9

10 Table 2. Quality assurance material performance data - accuracy referred to skim

11 milk powder BCR-063R certified reference material (average from three analytical 12 runs).

\begin{tabular}{|l|l|l|l|}
\hline Element & Certified value & \multicolumn{1}{|c|}{$\begin{array}{c}\text { Found value } \\
(\mathrm{mg} / \mathrm{g})\end{array}$} & $\begin{array}{c}\text { Accuracy } \\
(\%)\end{array}$ \\
\hline $\mathrm{Ca}$ & $13.49(\mathrm{mg} / \mathrm{g}) \pm 0.10$ & $13.56 \pm 0.09$ & 100.5 \\
\hline $\mathrm{Fe}$ & $2.32(\mathrm{\mu g} / \mathrm{g}) \pm 0.23$ & $3.48 \pm 2.64$ & 150 \\
\hline $\mathrm{K}$ & $17.68(\mathrm{mg} / \mathrm{g}) \pm 0.19$ & $16.56 \pm 0.04$ & 93.7 \\
\hline $\mathrm{Mg}$ & $1.263(\mathrm{mg} / \mathrm{g}) \pm 0.024$ & $1.23 \pm 0.00$ & 97.4 \\
\hline $\mathrm{Na}$ & $4.37(\mathrm{mg} / \mathrm{g}) \pm 0.031$ & $5.52 \pm 0.05$ & 126.3 \\
\hline $\mathrm{P}$ & $11.10(\mathrm{mg} / \mathrm{g}) \pm 0.13$ & $10.32 \pm 0.31$ & 92.9 \\
\hline $\mathrm{Pb}$ & $18.50(\mathrm{ng} / \mathrm{g}) \pm 2.7$ & $18.10 \pm 1.27$ & 95.1 \\
\hline $\mathrm{Zn}$ & $49.00(\mu \mathrm{g} / \mathrm{g}) \pm 0.6$ & $39.38 \pm 4.59$ & 80.4 \\
\hline
\end{tabular}


Table 3. Element content (mean $\mu \mathrm{g} / \mathrm{g} \pm \mathrm{SD}$ ) in milk and Halloumi cheese from the three producing areas (Anogyra, Kofinou and Paphos).

\begin{tabular}{|c|c|c|c|c|c|c|}
\hline \multirow[b]{2}{*}{$\begin{array}{l}\text { Element Region } \\
\text { content }(\mu \mathrm{g} / \mathrm{g})\end{array}$} & \multicolumn{2}{|c|}{ Anogyra } & \multicolumn{2}{|c|}{ Kofinou } & \multicolumn{2}{|c|}{ Paphos } \\
\hline & $\begin{array}{l}\text { Milk } \\
(\mathrm{n}=7)\end{array}$ & $\begin{array}{l}\text { Halloumi cheese } \\
\qquad(\mathrm{n}=7)\end{array}$ & $\begin{array}{l}\text { Milk } \\
(\mathrm{n}=7)\end{array}$ & $\begin{array}{l}\text { Halloumi cheese } \\
\qquad(n=7)\end{array}$ & $\begin{array}{l}\text { Milk } \\
(\mathrm{n}=10)\end{array}$ & $\begin{array}{l}\text { Halloumi cheese } \\
\qquad(\mathrm{n}=7)\end{array}$ \\
\hline $\mathrm{Ag}$ & n.d. & $0.43^{\mathrm{a}} \pm 0.25$ & n.d. & $0.09^{\mathrm{b}} \pm 0.06$ & n.d. & $0.12^{\mathrm{b}} \pm 0.10$ \\
\hline $\mathrm{Al}$ & n.d. & $1.47^{\mathrm{a}} \pm 0.60$ & n.d. & $1.24^{\mathrm{a}} \pm 0.35$ & n.d. & $1.33^{\mathrm{a}} \pm 0.36$ \\
\hline B & $0.12^{\mathrm{a}} \pm 0.06$ & n.d. & $0.10^{\mathrm{a}} \pm 0.04$ & n.d. & $0.10^{\mathrm{a}} \pm 0.03$ & n.d. \\
\hline $\mathrm{Ba}$ & $0.04^{\mathrm{a}} \pm 0.03$ & $0.60^{\mathrm{b}} \pm 0.28$ & $0.11^{\mathrm{a}} \pm 0.06$ & $1.23^{\mathrm{a}} \pm 0.43$ & $0.12^{\mathrm{a}} \pm 0.12$ & $0.48^{\mathrm{b}} \pm 0.47$ \\
\hline Co & $0.14^{\mathrm{a}} \pm 0.01$ & $1.17^{\mathrm{a}} \pm 0.08$ & $0.14^{\mathrm{a}} \pm 0.01$ & $1.24^{\mathrm{a}} \pm 0.06$ & $0.16^{\mathrm{a}} \pm 0.03$ & $1.19^{\mathrm{a}} \pm 0.09$ \\
\hline $\mathrm{Fe}$ & $0.14^{\mathrm{a}} \pm 0.05$ & $2.57^{\mathrm{a}} \pm 2.15$ & $0.16^{\mathrm{a}} \pm 0.07$ & $1.37^{\mathrm{a}} \pm 0.82$ & $0.32^{\mathrm{a}} \pm 0.21$ & $1.79^{\mathrm{a}} \pm 0.93$ \\
\hline $\mathrm{Li}$ & $0.03^{\mathrm{a}} \pm 0.00$ & n.d. & $0.03^{\mathrm{a}} \pm 0.00$ & n.d. & $0.07^{\mathrm{b}} \pm 0.03$ & n.d. \\
\hline $\mathrm{Mn}$ & $0.09^{\mathrm{a}} \pm 0.04$ & $1.01^{\mathrm{a}} \pm 0.56$ & $0.04^{b} \pm 0.01$ & $0.37^{b} \pm 0.09$ & $0.05^{a . b} \pm 0.02$ & $0.32^{b} \pm 0.06$ \\
\hline Se & $0.31^{\mathrm{a}} \pm 0.05$ & $2.51^{\mathrm{a}} \pm 0.21$ & $0.25^{\mathrm{a}} \pm 0.17$ & $2.48^{\mathrm{a}} \pm 0.40$ & $0.32^{\mathrm{a}} \pm 0.05$ & $2.73^{\mathrm{a}} \pm 0.41$ \\
\hline $\mathrm{Sr}$ & $0.89^{\mathrm{b}} \pm 0.15$ & $7.26^{\mathrm{b}} \pm 1.31$ & $3.34^{\mathrm{a}} \pm 1.64$ & $25.15^{\mathrm{a}} \pm 11.22$ & $1.03^{\mathrm{b}} \pm 0.35$ & $6.74^{\mathrm{b}} \pm 1.36$ \\
\hline $\mathrm{Y}$ & $0.005^{\mathrm{a}} \pm 0.00$ & $0.05^{\mathrm{a}} \pm 0.02$ & $0.005^{\mathrm{a}} \pm 0.00$ & $0.04^{\mathrm{a}} \pm 0.002$ & $0.006^{\mathrm{a}} \pm 0.001$ & $0.04^{\mathrm{a}} \pm 0.001$ \\
\hline $\mathrm{Ca}$ & $929.3^{\mathrm{b}} \pm 52.9$ & $6976.5^{a . b} \pm 684.8$ & $785.9^{\mathrm{b}} \pm 127.6$ & $7568.4^{\mathrm{a}} \pm 776.3$ & $1228.5^{\mathrm{a}} \pm 333.3$ & $6583.4^{\mathrm{b}} \pm 745.6$ \\
\hline $\mathrm{K}$ & $1195.6^{\mathrm{a}} \pm 120.2$ & $2038.8^{\mathrm{a}} \pm 178.9$ & $1151.8^{\mathrm{a}} \pm 204.0$ & $1729.1^{\mathrm{b}} \pm 201$ & $1415.1^{\mathrm{a}} \pm 782.1$ & $1516.7^{\mathrm{b}} \pm 217.7$ \\
\hline $\mathrm{Mg}$ & $102.8^{\mathrm{a}} \pm 29.0$ & $288.6^{\mathrm{a}} \pm 36.6$ & $78.73^{\mathrm{a}} \pm 18.14$ & $349.6^{\mathrm{b}} \pm 125.2$ & $121.4^{\mathrm{a}} \pm 60.2$ & $236^{\mathrm{a}} \pm 51.8$ \\
\hline $\mathrm{Na}$ & $389.3^{\mathrm{a}} \pm 32.31$ & $10774^{\mathrm{a} \cdot \mathrm{b}} \pm 3557$ & $356.2^{\mathrm{a}} \pm 42.8$ & $7952.1^{\mathrm{b}} \pm 2966$ & $372.4^{\mathrm{a}} \pm 73.2$ & $16193^{\mathrm{a}} \pm 5822$ \\
\hline
\end{tabular}




\begin{tabular}{|l|c|c|c|c|c|c|}
\hline P & $720.5^{\mathrm{a}} \pm 66,9$ & $4786.4^{\mathrm{b}} \pm 348,6$ & $593.4^{\mathrm{a}} \pm 78,3$ & $5282.7^{\mathrm{a}} \pm 541,8$ & $815.0^{\mathrm{a}} \pm 278,5$ & $4686.6^{\mathrm{b}} \pm 388,8$ \\
\hline Zn & $1.77^{\mathrm{a}, \mathrm{b}} \pm 0.45$ & $26^{\mathrm{a}} \pm 8,6$ & $1.24^{\mathrm{b}} \pm 0,22$ & $25.2^{\mathrm{a}} \pm 11,7$ & $1.85^{\mathrm{a}} \pm 0,71$ & $31.7^{\mathrm{a}} \pm 9.1$ \\
\hline
\end{tabular}

$\mathrm{n}$ : number of samples

n.d.: not detected

${ }^{a, b}$ Different letters within a row indicate significant differences $(\mathrm{P}<0.05)$ between groups 
Table 4. Average element content ( $\mu \mathrm{g} / \mathrm{g}$ or $\mathrm{ppm})$ in plants samples, mainly forage, from the three producing areas.

\begin{tabular}{|c|c|c|c|c|c|c|c|c|c|c|c|c|c|c|c|c|c|}
\hline Plant species & $\mathrm{Ag}$ & $\mathrm{Al}$ & $\mathrm{B}$ & $\mathrm{Ba}$ & Co & $\mathrm{Fe}$ & $\mathrm{Li}$ & $\mathrm{Mn}$ & $\mathrm{Ni}$ & $\mathrm{Sr}$ & $\mathrm{Y}$ & $\mathrm{Ca}$ & $\mathrm{K}$ & $\mathrm{Mg}$ & $\mathrm{Na}$ & $\mathrm{P}$ & $\mathrm{Zn}$ \\
\hline $\begin{array}{l}\text { Pistacia } \\
\text { lentiscus (A) }\end{array}$ & 0.3 & 28.9 & 44.2 & 19.0 & 1.8 & 187.5 & 0.3 & 18.1 & 0.6 & 79.3 & 0.11 & 7235.4 & 5776.9 & 1471.8 & 2519.7 & 1188.1 & 10.0 \\
\hline $\begin{array}{l}\text { Ceratonia } \\
\text { siliqua (A) }\end{array}$ & 0.3 & 48.9 & 2019.8 & 45.2 & 3.0 & 1492.8 & 0.4 & 628.7 & 1.9 & 2309.6 & 0.19 & 22628.0 & 4396.6 & 1837.0 & 4267.6 & 910.1 & 10.3 \\
\hline $\begin{array}{l}\text { Malva sylvestris } \\
(\mathrm{K})\end{array}$ & 0.7 & 17.3 & 40.9 & 21.0 & 2.9 & 120.6 & 1.2 & 51.2 & 0.5 & 149.6 & 0.11 & 19888.1 & 26883.9 & 1319.2 & 4377.4 & 2568.5 & 27.7 \\
\hline $\begin{array}{l}\text { Myrtus } \\
\text { communis (P) }\end{array}$ & 0.8 & 37.8 & 74.8 & 0.5 & 1.8 & 151.0 & 0.3 & 25.1 & 0.7 & 7.0 & 0.16 & 7295.4 & 4446.9 & 2254.9 & 2278.2 & 717.9 & 9.4 \\
\hline $\begin{array}{l}\text { Olea europaea } \\
\text { (P) }\end{array}$ & 1.7 & 16.6 & 8.0 & 0.2 & 1.7 & 80.4 & 0.2 & 19.7 & 0.6 & 6.7 & 0.12 & 8228.5 & 4427.1 & 1155.1 & 2266.8 & 766.6 & 8.6 \\
\hline $\begin{array}{l}\text { Thymus } \\
\text { capitatus }(\mathrm{P})\end{array}$ & 2.2 & 52.4 & 19.3 & 4.3 & 2.4 & 176.8 & 0.5 & 34.3 & 0.6 & 11.4 & 0.18 & 13972.1 & 8303.4 & 2315.4 & 2904.2 & 1147.7 & 24.2 \\
\hline Inula viscosa $(\mathrm{P})$ & 1.2 & 45.7 & 59.8 & 1.8 & 2.1 & 187.1 & 1.0 & 165.8 & 1.6 & 19.9 & 0.16 & 8503.5 & 15679.2 & 1089.2 & 5767.9 & 2241.8 & 18.6 \\
\hline $\begin{array}{l}\text { Cistus creticus } \\
\text { (P) }\end{array}$ & 1.2 & 74.5 & 31.8 & 2.4 & 2.5 & 244.3 & 0.5 & 47.5 & 1.0 & 13.2 & 0.19 & 12215.4 & 6884.4 & 1536.9 & 2081.3 & 1483.8 & 42.4 \\
\hline $\begin{array}{l}\text { Sarcopoterium } \\
\text { spinosum }(\mathrm{P})\end{array}$ & 0.2 & 70.4 & 31.8 & 2.0 & 2.4 & 252.5 & 0.5 & 38.9 & 0.8 & 14.9 & 0.22 & 13125.5 & 8108.5 & 3078.2 & 2208.7 & 1335.9 & 13.2 \\
\hline $\begin{array}{l}\text { Crataegus } \\
\text { azarolus }(\mathrm{P})\end{array}$ & 1.0 & 8.2 & 32.5 & 0.6 & 1.8 & 66.7 & 0.2 & 26.2 & 0.4 & 5.8 & 0.11 & 6161.0 & 12308.7 & 1723.2 & 2371.9 & 1500.3 & 15.5 \\
\hline $\begin{array}{l}\text { Quercus } \\
\text { coccinea }(\mathrm{P})\end{array}$ & 0.5 & 27.1 & 46.4 & 0.6 & 1.5 & 109.6 & 0.7 & 326.8 & 0.7 & 5.8 & 0.11 & 6122.9 & 2655.1 & 1017.4 & 2195.4 & 821.2 & 12.4 \\
\hline $\begin{array}{l}\text { Helichrysum } \\
\text { italicum }(\mathrm{P})\end{array}$ & 0.3 & $\begin{array}{c}1028 \\
3.9\end{array}$ & 31.7 & 3.0 & 2.7 & $\begin{array}{c}26507 . \\
7\end{array}$ & 1.7 & $\begin{array}{c}1333 . \\
9\end{array}$ & 3.3 & 12.6 & 0.59 & 8711.5 & 8529.1 & 2624.1 & 4889.9 & 967.4 & 13.3 \\
\hline $\begin{array}{l}\text { Mixture } \\
\text { (Plantago } \\
\text { lanceolata. }\end{array}$ & 0.5 & 72.6 & 5.5 & 0.5 & 1.7 & 303.6 & 0.3 & 37.1 & 1.2 & 7.7 & 0.14 & 3947.6 & 18622.2 & 1389.2 & 2844.9 & 1625.7 & 16.9 \\
\hline
\end{tabular}




\begin{tabular}{|l|l|l|l|l|l|l|l|l|l|l|l|l|l|l|l|l|l|l|l|l|l|}
\hline $\begin{array}{l}\text { Medicago } \\
\text { truncatula) (P) }\end{array}$ & & & & & & & & & & & & & & & \\
\hline
\end{tabular}

(A): Anogyra; (K): Kofinou; (P): Paphos 




Figure 1. Box plot showing Sr concentration values from milk produced in different regions and under different production systems. (Line in the centre, median; box, 25$75^{\text {th }}$ percentile; whisker, minimum non-outlier - maximum non-outlier. Symbols out of the boxplots: outliers, circles; extreme outliers, asterisks). 


\section{Loading value in PC1}



Groups OAnogyra $\quad$ GKofinou $\quad \Delta$ Paphos +variables

Figure 2. Principal component analysis on milk samples $(n=24)$. Biplot of principal component scores and loadings. 
Table 3. Results of the classification of milk samples from different production regions of Cyprus on the basis of canonical discriminant analysis by means of $\mathrm{Ca}$, $\mathrm{Sr}$, and $\mathrm{Zn}^{\mathrm{a}}$.

\begin{tabular}{|c|c|c|c|c|c|c|}
\hline & & \multirow[b]{2}{*}{ Origin } & \multicolumn{3}{|c|}{ Predicted Group Membership } & \multirow[b]{2}{*}{ Total } \\
\hline & & & Anogyra & Kofinou & Paphos & \\
\hline \multirow{6}{*}{ Original } & \multirow{4}{*}{ Count } & Anogyra & 7 & 0 & 0 & 7 \\
\hline & & Kofinou & 1 & 6 & 0 & 7 \\
\hline & & Paphos & 2 & 0 & 10 & 12 \\
\hline & & Anogyra & 100.0 & 0.0 & 0.0 & 100.0 \\
\hline & \multirow[t]{2}{*}{$\%$} & Kofinou & 14.3 & 85.7 & 0.0 & 100.0 \\
\hline & & Paphos & 16.7 & 0.0 & 83.3 & 100.0 \\
\hline \multirow{6}{*}{ Cross-validated } & \multirow{4}{*}{ Count } & Anogyra & 7 & 0 & 0 & 7 \\
\hline & & Kofinou & 0 & 5 & 2 & 7 \\
\hline & & Paphos & 0 & 0 & 12 & 12 \\
\hline & & Anogyra & 100.0 & 0.0 & 0.0 & 100.0 \\
\hline & \multirow[t]{2}{*}{$\%$} & Kofinou & 0.0 & 71.4 & 28.6 & 100.0 \\
\hline & & Paphos & 0.0 & 0.0 & 100.0 & 100.0 \\
\hline
\end{tabular}

a $88.5 \%$ of original grouped cases correctly classified. $92.3 \%$ of cross-validated grouped cases correctly classified. 




Figure 3. Plot showing the first two discriminant functions derived from milk samples produced in three different regions of Cyprus after canonical discriminant analysis. 
Table 4. Results of the classification of Halloumi cheese samples from different production regions of Cyprus on the basis of canonical discriminant analysis by means of $\mathrm{Sr}, \mathrm{K}$ and $\mathrm{Mn}^{\mathrm{a}}$.

\begin{tabular}{|c|c|c|c|c|c|c|}
\hline & & \multirow[b]{2}{*}{ Origin } & \multicolumn{3}{|c|}{ Predicted group membership } & \multirow[b]{2}{*}{ Total } \\
\hline & & & Anogyra & Kofinou & Paphos & \\
\hline \multirow{6}{*}{ Original } & \multirow{4}{*}{ Count } & Anogyra & 7 & 0 & 0 & 7 \\
\hline & & Kofinou & 0 & 7 & 0 & 7 \\
\hline & & Paphos & 0 & 0 & 9 & 9 \\
\hline & & Anogyra & 100.0 & 0.0 & 0.0 & 100.0 \\
\hline & \multirow[t]{2}{*}{$\%$} & Kofinou & 0.0 & 100.0 & 0.0 & 100.0 \\
\hline & & Paphos & 0.0 & 0.0 & 100.0 & 100.0 \\
\hline \multirow{6}{*}{ Cross-validated } & \multirow{4}{*}{ Count } & Anogyra & 7 & 0 & 0 & 7 \\
\hline & & Kofinou & 0 & 6 & 1 & 7 \\
\hline & & Paphos & 0 & 0 & 9 & 9 \\
\hline & & Anogyra & 100.0 & 0.0 & 0.0 & 100.0 \\
\hline & \multirow[t]{2}{*}{$\%$} & Kofinou & 0.0 & 85.7 & 14.3 & 100.0 \\
\hline & & Paphos & 0.0 & 0.0 & 100.0 & 100.0 \\
\hline
\end{tabular}




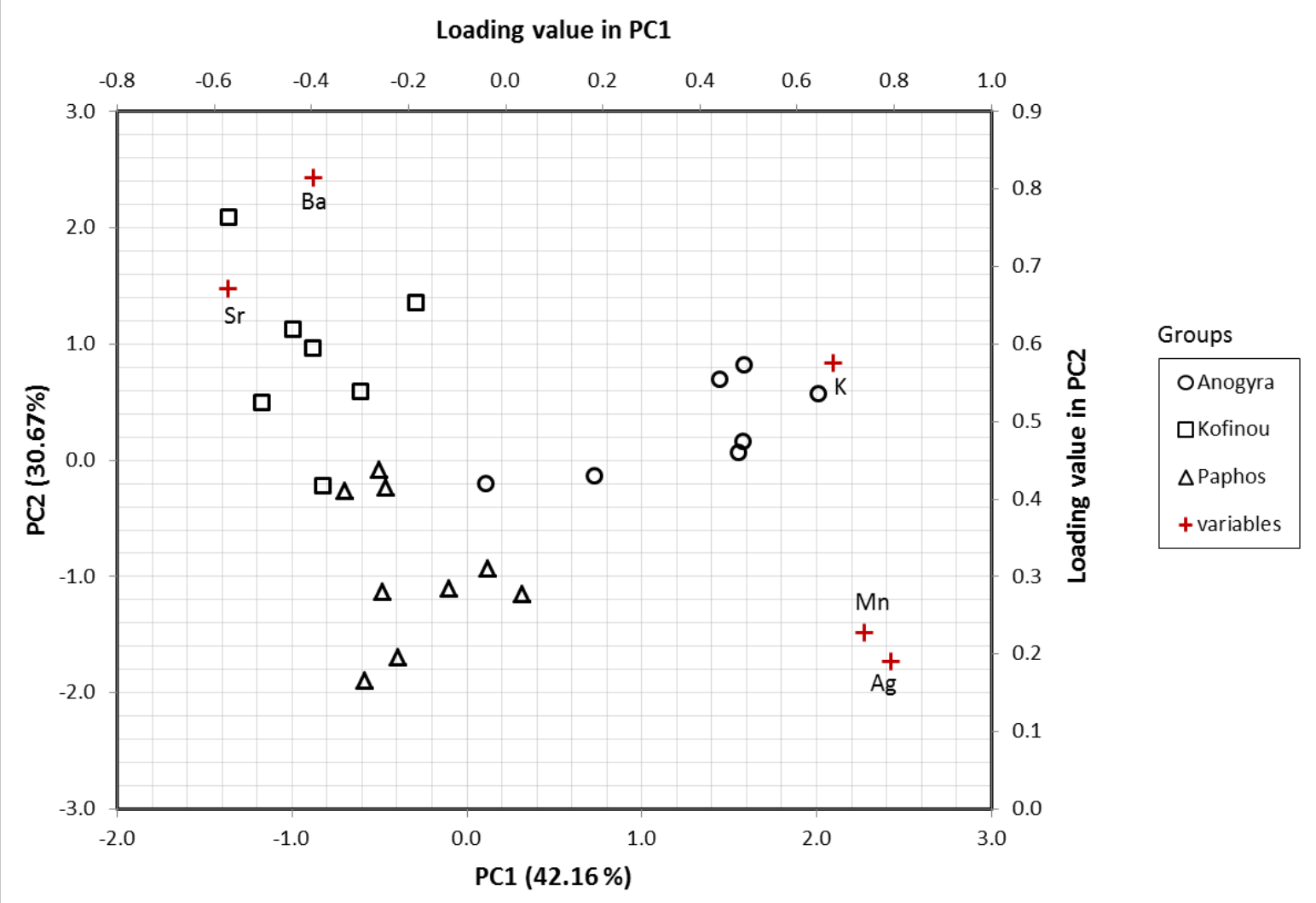

Figure 4. Principal component analysis on Halloumi cheese samples ( $\mathrm{n}=23)$. Biplot of principal component scores and loadings. 


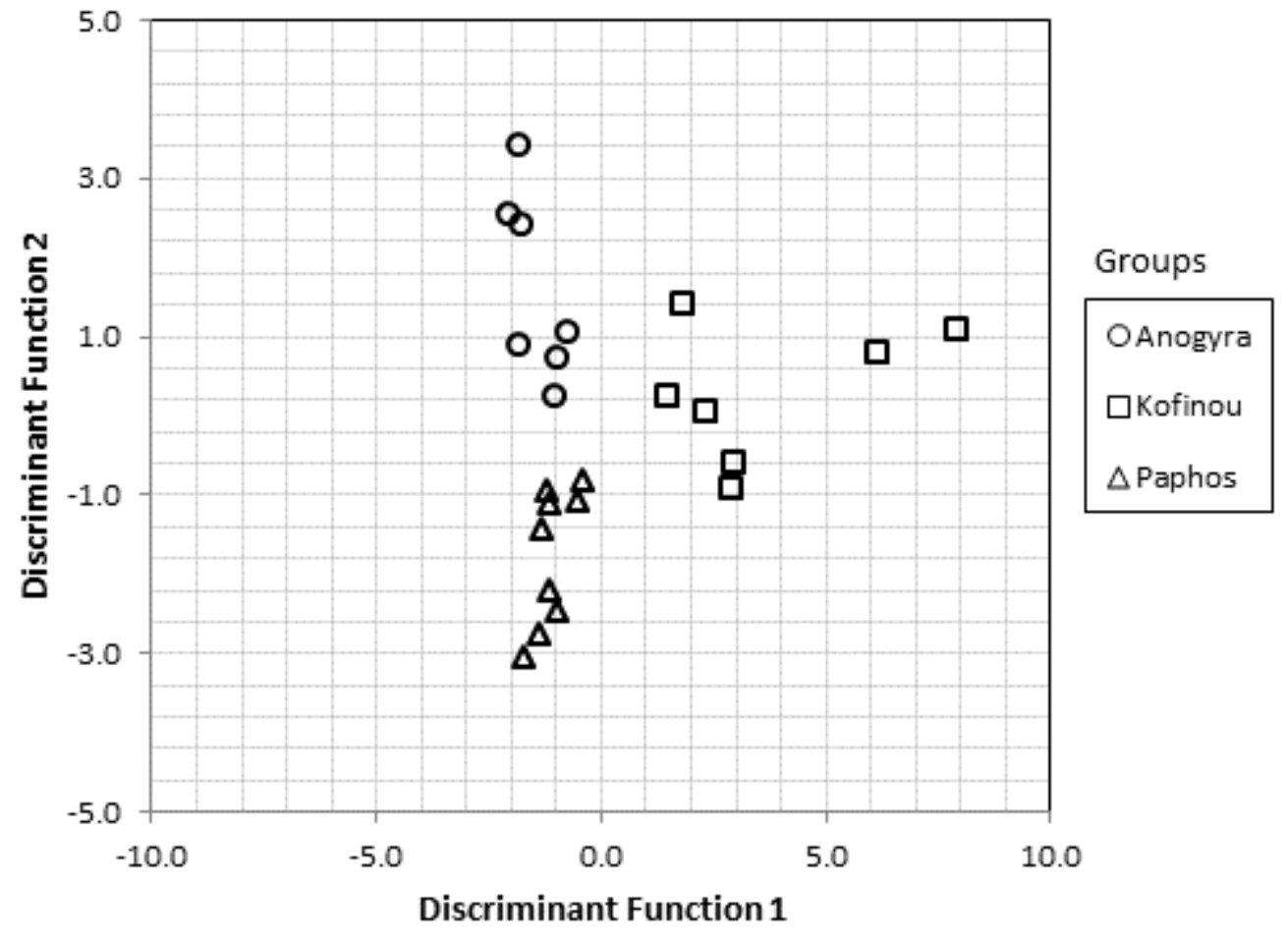

Figure 5. Canonical discriminant analysis plot showing the first two discriminant functions derived from Halloumi cheese samples produced in three different areas of the island. 


\section{REFERENCES}

1. Agabriel, C., Cornu, A., Journal, C., Sibra, C., Grolier, P., \& Martin, B. (2007). Taker milk variability according to farm feeding practices: vitamins A and E, carotenoids, color, and terpenoids. Journal of Dairy Science, 90(10), 4884-4896.

2. Ariyama, K., Aoyama, Y., Mochizuki, A., Homura, Y., Kadokura, M., \& Yasui, A. (2007). Determination of the geographic origin of onions between three main production areas in Japan and other countries by mineral composition. Journal of Agricultural and Food Chemistry, 55, 347-354.

3. Benincasa, C., Lewis, J., Sindona., G., \&Tagarelli, A (2008) The use of multi element profiling to differentiate between cow and buffalo milk. Food Chemistry, 110(1), 257-262.

4. Bontempo, L., Larcher, R., Camin, F., Hölzl, S., Rossmann, A., Horn, P., \& Nicolini, G. (2011). Elemental and isotopic characterisation of typical Italian alpine cheeses. International Dairy Journal, 21, 441-446.

5. Cohen D. R., Rutherford N. F., Morisseau E, \& Zissimos A. M. (2011) Geochemical Atlas of Cyprus. Sydney:UNSW Press

6. Chope, G. A., Terry, L. A. (2009). Use of canonical variate analysis to differentiate onion cultivars by mineral content as measured by ICP-AES. Food Chemistry, 115, 1108-1113.

7. Coetzee, P. P., Steffens, F. E., Eiselen, R. J., Augustyn, O. P., Balcaen, L., \& Vanhaecke, F. (2005). Multi-element analysis of South African wines by ICP-MS and their classification according to geographical origin. Journal of Agricultural and Food Chemistry, 53, 5060-5066.

8. Collomb, M., Bütikofer, U., Sieber, R., Jeangros, B., \& Bosseta J.-O. (2002) Correlation between fatty acids in cows' milk fat produced in the Lowlands, Mountains and Highlands of Switzerland and botanical composition of the fodder. International Dairy Journal, 12, 661-666.

9. Coni, E., Bocca, A., Coppolelli, P., Caroli, S., Cavallucci, C., \& Marinucci, M. T. (1996). Minor and trace element content in sheep and goat milk and dairy products. Food Chemistry, 57(2), 253-260.

10. Furia, E., Naccarato, A., Sindona, G., Stabile, G., \& Tagarelli, A. (2011). Multielement fingerprinting as a tool in origin authentication of PGI food products: Tropea red onion. Journal of Agricultural and Food Chemistry, 59, 8450-8457. 
11. García, M. I. H., Puerto, P. P., Baquero, M. F., Rodríguez, E. R., Martín, J. D., \& Romero, C. D. (2006). Mineral and trace element concentrations of dairy products from goats' milk produced in Tenerife (Canary Islands). International Dairy Journal, 16(2), 182-185.

12. Herrera, M. I., Peláez, P., Fresno, M., Rodríguez, E., Darías, J., Díaz C. (2006). Mineral and trace element concentrations of dairy products from goats' milk produced in Tenerife (Canary Islands). International Dairy Journal, 16, 182-185.

13. Lo Feudo, G., Naccarato, A., Sindona, G., \& Tagarelli, A. (2010). Investigating the origin of tomatoes and triple concentrated tomato pastes through multielement determination by inductively coupled plasma mass spectrometry and statistical analysis. Journal of Agricultural and Food Chemistry, 58, 3801-3807.

14. Mariaca, R.G., Berger, T.F.H., Gauch, R., Imhof, M.I., Jeangros, B. \& Bosset, J.O. (1997). Occurrence of volatile mono- and sesquiterpenoids in highland and lowland plant species as possible precursors for flavor compounds in milk and dairy products. Journal of Agricultural Food Chemistry, 45, 4423-4434.

15. Morand-Fehr, P., Fedele, V., Decandia, M., Le Frileux, Y. (2007). Influence of farming and feeding systems on composition and quality of goat and sheep milk. Small Ruminant Research, 68, 20-34.

16. Moreda-Piñeiro, A., Fisher, A., \& Hill, S. J. (2003). The classification of tea according to region of origin using pattern recognition techniques and trace metal data. Journal of Food Composition and Analysis, 16(2), 195-211.

17. O’Connell, J. E., \& Fox,P. F. (2001). Significance and applications of phenolic compounds in the production and quality of milk and dairy products: a review. International Dairy Journal, 11, 103-120.

18. Papademas, P. (2006) Halloumi cheese. In: A.Y. Tamime (Ed.), Brined Cheeses, (pp.117-138) Oxford, UK:Blackwell Publishing Ltd

19. Pillonel, L., Ampuero, S., Tabacchi, R., \& Bosset, J. O. (2003). Analytical methods for the determination of the geographic origin of Emmental cheese Volatile compounds by GC/MS-FID and electronic nose. European Food and Research Technology, 216, 179-183.

20. Regulation (EU) No 1151/2012 of the European Parliament and of the council of 21 November 2012 on quality schemes for agricultural products and foodstuffs. 
21. Sacco, D., Brescia, M. A., Sgaramella, A., Casiello, G., Buccolieri, A., Ogrinc, N., et al. (2009). Discrimination between Southern Italy and foreign milk samples using spectroscopic and analytical data. Food Chemistry, 114, 1559-1563.

22. Statistical Service, Ministry of Finance, Republic of Cyprus (2014)

23. Suhaj, M., Koreňovská, M. (2008). Correlation and distribution of elemental markers of origin in the production of Bryndza sheep cheese. Food Chemistry, 107, 551-557.

24. Taylor, V.F., Longerich, H.P., Greenough, J.D. (2003). Multielement analysis of Canadian wines by inductively coupled plasma mass spectrometry (ICP-MS) and multivariate statistics. Journal of Agricultural and Food Chemistry, 51, 856-860.

25. Zeppa, G., Giordano, M., Lombardi, G., Gerbi, V. (2003). Use of terpene profiles for the mountain pastures characterization. In: Proceedings of the First Joint Seminar of the FAO-CIHEAM Sheep and Goat Nutrition and Mediterranean Pasture Sub-Networks 'Sustainable Grazing, Nutritional Utilization and Quality of Sheep and Goat products’, Granada, Spain, pp. 106. 